\section{B A Institute of \\ YK Business Administration \\ TK \\ Karachi \\ Leadership and Ideas for Tomorrow}

Business Review

Volume 5 Issue 1 January-June 2010

$1-1-2010$

\title{
Reasons for construction firms transiting to ISO 9001:2008 Quality Management Systems
}

\author{
Low Sui Pheng \\ Department of Building, National University of Singapore, Singapore \\ Alfred Hah \\ Department of Building, National University of Singapore, Singapore
}

Follow this and additional works at: https://ir.iba.edu.pk/businessreview

Part of the Business Administration, Management, and Operations Commons, and the Management Sciences and Quantitative Methods Commons

\section{(c) (1)}

This work is licensed under a Creative Commons Attribution 4.0 International License.

\section{Recommended Citation}

Pheng, L. S., \& Hah, A. (2010). Reasons for construction firms transiting to ISO 9001:2008 Quality Management Systems. Business Review, 5(1), 23-38. Retrieved from https://doi.org/10.54784/ 1990-6587.1255 


\title{
ARTICLE
}

\section{Reasons For Construction Firms Transiting To ISO 9001:2008 Quality Management Systems}

\author{
Low Sui Pheng and Alfred Hah \\ Department of Building \\ National University of Singapore, Singapore
}

\begin{abstract}
The International Organization for Standardization (ISO) is a worldwide federation of national standards bodies from approximately 162 countries. ISO is also a non-governmental organization that forms the missing link between the public and private sectors. With increasing awareness and attention on delivering quality and desirable products to the end users, ISO certification has increasingly become an important benchmark and confidence for both the organization and its customers. To keep up with the evolution and advancement in the different industries such as manufacturing, hospitality and construction, and also to satisfy higher customer's expectations, ISO has to constantly improve and renew its standards. Consequently, with respect to quality management, an updated version of ISO 9001:2000 was issued recently in 2008. The current applicable standard is thus the ISO 9001:2008 relating to quality management systems. ISO 9001:2008 does not evolve from a major overhaul of ISO 9001:2000. Instead, it introduces significant clarification to the requirements stated in ISO 9001:2000. This study examines the willingness and receptiveness of large construction firms in Singapore to transit to the new ISO 9001:2008 standard. It also evaluates organization behavior that motivates construction firms to make the transition to the new ISO 9001:2008 standard.
\end{abstract}

Keywords: Quality management, ISO 9001:2008, Construction firms, Organization behavior

\section{Introduction}

The International Organization for Standardization (ISO) was founded in 1946 in Geneva, Switzerland. Its purpose was to establish a common worldwide standard for manufacturing, communication and trade. One of the key roles of the ISO is to publish and disseminate good practice standards for worldwide adoption across nations. An important standard released by the ISO relates to the ISO 9000 standards for quality management systems.

It should however be noted that the ISO 9000 standards are not product standards and are not prescriptive in nature. However, the ISO 9000 standards define the requirements for quality management and quality assurance systems that are used by companies for the purpose of providing good services and products to customers. The certification started out on a voluntary basis but in today's context, a company without an ISO 9000 
certification will lose its competitive edge and credibility. In addition, it is a requirement that customers will look for when doing business or entering into a contract.

In Singapore's context, the Building and Construction Authority (BCA) launched the ISO 9000 certification scheme way back in 1991. The objective of this scheme was to promote the adoption of an international quality management system standard in Singapore's construction industry. Since July 1, 1999, top contractors and consultants have been required to obtain ISO 9000 certification which will enable them to tender for public sector projects above $\mathrm{S} \$ 30$ million. It is also mandatory for construction firms which are classified under the larger A1, A2, B1 and B2 categories within BCA to obtain ISO 9000 certification. This requirement set out by BCA helps to create a more productive and efficient quality management system and environment within the organization. This helps to ensure that the company will be able to deliver good quality work and products consistently.

A majority of the construction firms in Singapore are ISO 9001:2000 certified. An updated version of the ISO 9001:2000 standard was been released recently. The new ISO 9001:2008 standard will replace the existing ISO 9001:2000 certification. The intention of the updated version is not to overwrite or replace the requirements stated in ISO 9001:2000. To bring about clarification and also increase its compatibility with ISO 14001 for Environmental Management Systems.

The Singapore Accreditation Council (SAC) released a notice on 22 January 2009 to state that construction firms would be given two years to conform with the new ISO 9001:2008 standards. This means that all accredited new certifications or re-certifications will have to adhere to the new ISO 9001:2008 version from mid-November 2009, a year from its publication in mid November 2008. And within two years, which is from mid-November 2010, accredited certifications to the existing ISO 9001:2000 version will no longer be valid.

The aim of this study is to investigate the readiness and willingness of construction firms when it comes to transiting to the new ISO 9001:2008 standards from the prevailing ISO 9001:2000 standards. The objectives of this research are:

1. To highlight the differences between ISO 9001:2000 and ISO 9001:2008.

2. To understand the reasons for construction firms transiting (or not transiting to ISO 9001:2008).

\section{ISO 9000 Guiding Principles}

ISO 9000 is a set of criteria that can be applied to all organizations regardless of type, size, product or service provided by these organizations. When applied correctly, these standards will help an organization develop the capability to create and retain satisfied customers and other stakeholdders (Hoyle, 2009). ISO 9000 also refers to a set of three standards which are ISO 9000, ISO 9001 and ISO 9004. All three standards are referred to as quality management system standards. ISO 9000 discusses the definition and terminology and is used to clarify the concepts used by ISO 9001 and ISO 9004 
standards. ISO 9001 contains requirements and is often used for certification purposes while ISO 9004 presents a set of guidelines and is used to develop quality management systems that go beyond ISO 9001.

ISO 9000 is important to organizations because it provides a platform for them to compete and excel internationally. It is supported by the national standards bodies from over 150 countries. It has become a benchmark that every customer would look for when doing business internationally. It brings about efficiency, productivity and good quality products and services. Only with a good quality management system, then can there be a world class standard of quality.

Historically, ISO 9001:1994 consisted of the following 20 quality system elements:

1. Management Responsibility

2. Quality System

3. Contract Review

4. Design Control

5. Document and Data Control

6. Purchasing

7. Purchaser (Customer) Supplied Product

8. Product Identification

9. Process Control

10. Inspection and Testing

11. Control of Inspection, Measuring and Test Equipment

12. Inspection and Test Status

13. Control of nonconforming product

14. Corrective and Preventive Action

15. Handling, Storage, Packaging, Preservation and Delivery

16. Control of Quality Records

17. Internal Quality Audits

18. Training

19. Servicing

20. Statistical Techniques

The ISO 9001:2000 standard is a far more generic standard than the earlier 1994 standard with the 20 elements annotated above. It adopts the process management approach which is widely used in business today and which more clearly addresses the Quality Management System (QMS) requirements for an organization to show its capability for meeting customer requirements (Tricker, 2006). ISO 9001:2000 is more flexible and does not imply uniformity of quality management systems; as such, it does not imply a requirement to change the structure of quality management system documentation (Weallans, 2000; Stapp, 2001). In addition, the ISO 9001:2000 standard is also made more compatible with the ISO 14000 series of standards for environmental management as well as national/international health and safety management standards (Tricker, 2006). 
ISO 9001:2000 underwent a major overhaul which changed its requirements, sections and approach towards quality management systems. Hoyle (2000) observed that the reasons for the changes are due to the following:

1. Process models became more prominent in quality management.

2. There was confusion on adoption and implementation requirements from different standards within the ISO family and also for different organizations of different nature.

3. Smaller firms experienced difficulties in interpreting and understanding the requirements.

4. The debate as to the associated business benefits.

5. The previous standard was not closely compatible with ISO 14000.

ISO 9001:2000 was more customer oriented. It placed greater emphasis on customer's expectations and satisfaction. Greater improvement in business performance can be achieved through positive customer experience. The standard adopted five auditable clauses and eight quality management principles which top management in the organization can use to improve performance and efficiency. The five auditable clauses are:

1. Quality management system

2. Management responsibility

3. Resource management

4. Product realization

5. Measurement, analysis and improvement

The eight quality management principles in ISO 9001:2000 are:

\section{Customer focus}

Customer requirements need to be determined and fulfilled with an intent to achieve customer satisfaction.

\section{Leadership}

Leaders establish unity of purpose and direction for the organization. They should create and maintain an internal environment in which people can become fully involved in achieving the organization's objectives.

\section{Involvement of people}

People at all levels are the essence of an organization and their full involvement enables their abilities to be used for the organization's benefit.

\section{Process approach}

A desired result is achieved more efficiently when activities and related resources are managed as a process.

\section{System approach to management}

Identifying, understanding and managing interrelated processes as a system contribute to the organization's effectiveness and efficiency in achieving its objectives. 


\section{Continual improvement}

Continual improvement of the organization's overall performance should be a permanent objective of the organization.

\section{Factual approach to decision making}

Effective decisions are based on the analysis of data and information.

\section{Mutually beneficial supplier relationships}

An organization and its suppliers are interdependent and a mutually beneficial relationship enhances the ability of both to create value.

Top management can use these eight quality management principles to lead the organization towards improved performance (Tricker, 2006).

\section{ISO 9001:2008}

The ISO 9001:2008 standard was officially published on 14 November 2008. There are perceptibly no major differences between the 2000 and 2008 versions of the standard. ISO 9001:2008, however, provides better clarity and compatibility with ISO 14001. It also provide organizations with continual improvement and effective quality management systems to operate more efficiently.

It is a general principle for the ISO to regularly revise its ISO standards every three years from the day it was published. In this manner, the standard will always be up to date with the latest developments in management system practices. These reasons led to the publication of ISO 9001:2008. This current ISO standard improves translatability and maintains consistency with the ISO 9000 family of standards. The clauses that have undergone more significant changes include:

\section{? 0.1 General \\ ? 6.3 Infrastructure \\ ? 7.2.1 Determination of requirements related to the product \\ ? 7.5.4 Customer property \\ ? 7.6 Control of monitoring and measuring equipment}

ISO 9001:2008 provides compatibility with ISO 14001, whose clauses and requirements are now in sync with each other. This synchronization brings about flexibility and a more systematic process of documentation and implementation. In the process, this also encourages the organization to strive towards ISO 14001 certification as well. 


\section{Organizational Behavior}

Organization behavior is a field of study that investigates the impact that individuals, groups and structures have on behavior within the organization. This impact works towards improving or adversely affecting the organization's effectiveness. It is also seen as a way to provide a behavioral approach to management. One of the most important parts of an organization relates to manpower, the people who make up and run the organization. Be it an individual or a group, people form a necessary part of any behavioral situation. Managing and controlling organization behavior is easier said than done. It deals with people, and often, emotions, culture, background, expectations, perceptions and personalities are involved. This is the reason why organization behavior is complex and interesting. Organizational behavior is interesting because it is about people and human nature (Miner, 2007). Hackman, Lawler and Porter (1983) noted that the task of getting organizations to function effectively can be a difficult one.

Understanding organization behavior cannot be achieved by just reading, documenting or implementing a system. It involves managing relationships in the organization and knowing how people may feel, think or react to certain decisions and actions. Hence, being able to maintain healthy relationships among employees, and also between employees and the management, helps to steer the organization as a united body towards its goals and objectives. People shape organizations and organizations influence people (Thompson, 2007).

Being able to grasp the whole idea of managing organization behavior will not only help manage people and spur the organization towards its goals; it will also help the organization to improve. Any problems can be identified by the managers and they will know the right way to resolve them efficiently and effectively. With motivated people with the right attitude in the organization, the organizational performance can be enhanced (Hersey, Blanchard and Johnson, 2000).

\section{Three Pillar Framework}

Scott's (2001) three pillar framework is made up of the regulatory pillar, the normative pillar and the cultural-cognitive pillar. This provides further elaboration on organization behavior. The framework can be seen as mutually reinforcing and complementing one another in an organization. Although such an inclusive model has its advantages and strengths, it also masks important differences (Scott, 2001). The three pillars function in different manners within an organization. There is no one better option over the other, but each may work better in a particular environment compared to another. Each pillar has its own definition of managing an organization and its quality system. Table 1 summarizes the three pillars and their respective constituents. 


\section{(a) Regulatory Pillar}

Rules are common in organizations. These help to monitor and ensure that things are done properly and correctly. Related activities can include the manipulation and use of sanctions, checking on conformity to the rules that are established, etc. Rewards and punishments can also be meted out respectively for good practices or violation of rules.

Force, fear and expedience are among the key considerations in the regulatory pillar. The primary mechanism of control is coercion. With authority and relevant laws imposed, this will bring about submission from people for tasks to be completed in a more systematic manner. A stable system of rules, either formal or informal, backed by surveillance and sanctioning power, is one of the prevailing view of organizations (Scott, 2001).

\section{(b) Normative Pillar}

Social obligations and moral values play an important role in a normative environment. Normative control can also be described as a system of control. The system works through subjective attributes and dispositions, which people are made aware of, and are compatible with the maintenance of certain types of work organization. Everyone in an organization has different norms of doing things and with different value systems. However, these factors are flexible as different job requirements may cause them to develop roles. For example, a particular position in an organization (for example, the role of the quality manager) may have specified responsibilities and rights to accomplish its job requirements (Scott, 2001).

\section{(c) Cultural-cognitive Pillar}

In the cognitive paradigm, what an individual does is, in large part, a function of that individual's internal representation of the environment. The functioning process and nature of a cultural-cognitive organization can therefore be shaped by the environment. The cultural factors determine the manner in which social interests are defined and how the organization functions. In addition, individual values also play an important role for identify the characteristics of the individual and how his job performance (Scott, 2001).

The ISO 9001:2008 standard emphasizes on developing and maintaining a good quality management system. The process of transiting from ISO 9001:2000 to ISO 9001:2008 involves coordination between human resources, document control and within the entire organization. Scott's (2001) three pillar framework can help to explain the relationship between a good quality management system and the corresponding organization behavior. 


\section{Research Methodology}

A fieldwork was conducted to better understand the rationale for construction firms to transit from the ISO 9001:2000 standard to the current ISO 9001:2008 standard for quality management systems. Surveys and interviews were conducted with the A1, A2, B1 and B2 categories of construction firms registered with the Building and Construction Authority (BCA) in Singapore. These are generally amongst the largest construction firms operating in Singapore. The surveys were conducted via email which is more convenient and effective. Interviews with quality assurance managers were also conducted to obtain first hand information on who deal with various aspects of quality in the daily work routine.

The survey questionnaire was formulated with the following objectives in mind.

1. To understand if construction firms in Singapore are receptive towards the new ISO 9001:2008 standard for quality management systems during the transition period.

2. To understand how organization behavior explains involvement and decisions relating to quality management systems in construction firms during the transition period.

The survey was conducted with a random selection of construction firms classified under the A1, A2, B1 and B2 categories with the BCA. These categories of firms were chosen because they already have ISO 9000 certification in place. Hence, the question of transiting to the current ISO 9001: 2008 standard would be relevant for these firms.

Interviews help to provide a better understanding of how the quality management systems evolved in these firms in tandem with updating of the ISO 9001 standard. Two participants were selected for the interview. The interviewees must be in a senior position within the firm to be able to provide credible information. In addition, they must be familiar and involved with quality management systems and their implementation. A total of 102 survey questionnaires were sent to BCA-registered A1, A2, B1 and B2 construction firms. Of these, 31 completed questionnaires were returned, representing a response rate of about $30 \%$. The respondents were generally associated with quality management responsibilities in their organizations. Of these, 15 were from A1 firms, 6 were from A2 firms, 3 were from B1 firms and 7 were from B2 firms. All the firms that responded were ISO 9001:2000 certified and they were aware of the latest ISO 9001:2008 standards. Following a pilot study, the survey and interviews took place in mid-2009. 


\section{Survey Findings}

\section{Background information}

\section{(a) Intention to transit to ISO 9001:2008 certification}

2 out of 31 respondents $(6 \%)$ had no intention at the time of the survey to transit to ISO 9001:2008 certification. It appears that these two firms felt that their current ISO 9001:2000 was stable and did not therefore see the need to transit to the new version as there were also no significant difference which set the two standards apart. From another point of view, the two firms may have planned to transit to the ISO 9001:2008 in the future but not at the time of the survey in mid-2009.

\section{(b) Time Line for certification}

The following time-lines were reported by the respondents:

? Within one month - two respondents

? Within two to four months - ten respondents

? Within five to seven months - eleven respondents

? Eight months and more - eight respondents

A majority of eleven respondents planned to obtain ISO 9001:2008 certification within 5-7 months. This could be because the ISO 9001:2008 standard had been only published very recently and the firms needed time to understand their requirements before implementation. On the other hand, there appears to be a goal of these firms wanting to be ahead of their competitors in obtaining the certification first. Hence, it seems that the period of 5 to 7 months is a reasonable time period for these firms to obtain their certification to meet the new standard.

\section{(c) No intention to transit}

1 out of the 2 above-mentioned respondents who had no intention of transiting to the ISO 9001:2008 certification answered this question. The construction firm that responded stated that its quality management system was better compared to the standards in ISO 9001:2008. The respondent explained that the firm was able to survive because of the trust it has already gained from its clients.

\section{(d) Other certification obtained}

$25(80 \%)$ respondents have acquired both ISO 14000 and OHSAS 18000 certification. $2(6 \%)$ of the respondents have only ISO 14000 certification. 4 $(13 \%)$ of the respondents have ISO 14000, OHSAS 18000 and OHSMS certification. This appears to suggest that ISO 14000 is compatible with ISO 9001:2000. Most of the companies with ISO 9001:2000 certification have ISO 14000 certification as well. This is to meet the requirements set by the BCA for registration in the specified categories of construction firms in Singapore. 


\section{Regulatory Aspects}

\section{(a) Rules are important}

$15(48 \%)$ respondents felt that rules are important and the remaining $16(52 \%)$ respondents felt that it is very important to have rules in their organization. Different people may have different perceptions about rules. Rules can be beneficial to an organization as these help to ensure law and order in the daily routine. Rules make it easier to for the management and control of both the organization and its employees. On the other hand, others may feel that rules are too regimental and do not encourage flexibility. Employees may feel that their actions and contributions will be restricted or curtailed

\section{(b) Resistance towards rules}

$21(68 \%)$ respondents were for the implementation of rules in their construction firms. $10(32 \%)$ respondents were against that idea. It is difficult to draw an interpretation from these survey findings without first understanding the background and value systems of the respondents on both sides of the fence.

\section{(c) Rewards and incentives}

All the respondents stated that rewards and incentives were given to their employees to encourage good quality practices. This reinforces the traditionally held view that people are frequently motivated when there are benefits, rewards and recognition.

\section{(d) Punishments}

$17(55 \%)$ respondents felt that it is useful to implement punishments to manage employees within the organization. The remaining $14(45 \%)$ respondents did not see the benefits of imposing punishments. Punishments must be handled appropriately. It may induce fear among the employees and hinder innovative suggestions and improvements for the organization.

In summary, employees are usually motivated when there are incentives or benefits. No one likes to be governed by rules but from the survey, it appears that most companies know that having rules can help keep things in order and to achieve better organizational results.

\section{Normative Aspects}

\section{(a) Support from others}

$20(65 \%)$ respondents reported that there were no other persons involved in quality besides the quality management team in the organization. Only 11 (35\%) respondents reported that there were other people, in addition to the quality management team, who played a part in ensuring that quality is achieved in the organization. 


\section{(b) Standard operating procedures}

$26(88 \%)$ respondents reported that there were standard procedures to handle quality related issues. Only $5(12 \%)$ respondents stated otherwise. Standard routines and procedures help to promote productivity. Tasks can be undertaken faster and more systematically. However, the standard procedures may cause the organization to stagnate. This is because of the lack of a culture that constantly strives for improvements and innovations.

\section{(c) Importance of ISO 9001 certification}

28 out of the 31 respondents indicated that ISO certification is important for the company. A minority 3 out of the 31 respondents indicated that the ISO certification is not important. ISO 9001:2008 may not have been perceived as important to the construction firms at the time of the survey because they already had a quality management system within their organizations that is anchored on ISO 9001:2000. The eventual transition to ISO 9001:2008 was therefore not perceived to be urgent at that point in time. Nevertheless, more construction firms should transit to the current ISO 9001:2008 standard as soon as they are able to.

\section{(d) Employee obligations}

$16(52 \%)$ respondents reported that employees felt obligated to play their part in quality management in the company. The remaining 15 (48\%) respondents stated that the employees did not feel obligated to share the company's vision in providing a good quality management system. An efficient quality management system requires the involvement and commitment of the entire organization. It is necessary to create a culture within the organization where the employees can feel that they are part of the organization and that they have responsibilities and contributions towards the quality management system.

\section{(e) Top management support}

29 respondents reported that top management was supportive of quality management. On the other hand, the remaining 2 respondents reflected that top management was not interested in quality management.

In summary, top management needs to be involved in managing quality in the organization. Top management must set an example for the employees to follow. This is to ensure that every employee will feel attached to the company and will realize that they have a part to play to achieve a good quality management system.

\section{Cultural-cognitive Aspects}

\section{(a) Organization culture}

$25(81 \%)$ respondents indicated that the organization's culture and practice do 
play an important role in promoting quality management. However, 6 (19\%) respondents felt otherwise. A conducive environment and positive organization culture can provide a platform for employees to learn and take up an active role towards contributing to the overall well-being and work procedures within the organization.

\section{(b) Standard routines}

27 respondents stated that routines would hinder improvements in the organization. 4 respondents stated that routines would not hinder improvements within the organization.

\section{(c) Implementation of belief}

$14(45 \%)$ respondents indicated that the organization does not implement a set of beliefs or culture for this employees. 17 (55\%) respondents said that the organization had implemented a set of beliefs and culture within the organization.

In summary, the organization needs to have the right attitude and environment for improvement and advancement. The organization must also be able to introduce and implement beneficial changes.

\section{Other Issues}

\section{(a) Resources for transition}

All the respondents agreed that documentation, manpower, time and money would be needed in the company's efforts to transit to a new ISO platform. This happened during the transition from ISO 9000:1994 to ISO 9001:2000 as there were major changes in requirements and scope. However, the case of transiting from ISO 9001:2000 to ISO 9001:2008 may not be that exhaustive and taxing on the company's resources as there do not seem to be significant changes to the requirements in the transition.

\section{(b) Staying ahead}

A majority of the respondents (90\%) felt that it is important to be constantly updated with the latest ISO standards. In this manner, they will stay ahead of their competitors and also portray a better image for the company.

\section{Interview Findings}

Two in-depth interviews were also conducted as part of the study. These were conducted with two experienced building professionals in August 2009. The first interview was conducted with Ms. A who is a Principal Quality Assurance Engineer for a major US multinational corporation operating in Singapore. Ms. A's scope of work includes the following: 
1. Work with the project manager to establish and maintain the project quality management system.

2. Plan and conduct quality audits.

3. Work closely with management and the project team to resolve quality related issues.

4. Coordinate client's audits (quality, controls and compliance).

Ms. A mentioned that her company was already ISO 9001:2000 certified and that they were planning for the ISO 9001:2008 conversion by the year 2010. When asked if the ISO certification was beneficial to her company, she said that:

"With a well documented management system in place, process and role and responsibility are clearly spelled out and this enhances accountability."

It can be seen that ISO certification does help an organization to develop a more wholesome quality management system. As for ISO 9001:2008, there were no government incentives for companies to obtain the certification but transiting does help the organization improve its efficiency and productivity. Ms. A also gave a brief explanation on the main differences between ISO 9001:2000 and ISO 9001:2008:

"The new ISO 9001:2008 enhances clarity of ISO 9001:2000 without introducing new requirements. Some useful clarification to existing requirements and reinforcement of a risk based approach to quality management. The most substantial change is on the reviewing of the effectiveness of the corrective and preventive actions taken."

Resources such as manpower, training and money will be involved for transiting to a new ISO standard. However, it appears that the efforts to transit to ISO 9001:2008 were not as complex and tedious as previously thought. Ms. A commented that:

"No additional resources are needed. The owner defines the processes and writes the procedures. Everyone is the owner of the system.

Therefore improvement of the system is everyone's business.

Quality department is the custodian of the management system, including updating, promulgation and training to all employees."

It appears to be fairly flexible and easy to transit to the new ISO 9001:2008 according to Ms. A.

The second interview was conducted with Mr. T who is an Environmental and Safety Manager of a Japanese multinational corporation operating in Singapore. He had much experience with quality assurance positions in other companies before he joined his current company. His job scope included implementing and reviewing the company's quality management system.

Mr. T stated that transiting to ISO 9001:2008 was not as complex as one may think and most companies will obtain the ISO 9001:2008 certification eventually. He noted that: 
Very minimal, it is very easy to upgrade to ISO 9001:2008.

There aren't any major changes. Within a year, to see most of the construction companies to get ISO 9001:2008 certified, is possible."

However, Mr. T highlighted another important point: "It doesn't make any difference if you tell people you are
ISO 9001:2000 or ISO 9001: 2008 certified."

The reason may be due to the lack of government incentives and motivation to transit. Furthermore, ISO 9001:2008 does not involve any major changes in requirements. The management in the organization must also take ownership of the quality system and make wise decisions to invest in it. In addition, Mr. T commented that,

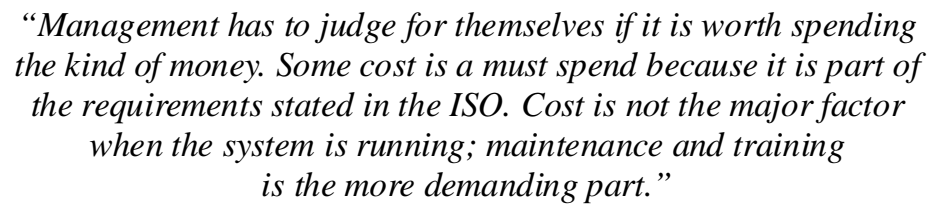

It can be seen that the areas which consume more resources are related to maintenance and training. It appears that the initial stage of implementing a quality system requires more resources. After it has been set up, it should run systematically and more attention should be placed on training personnel and managing the system. Mr. T added that:

"ISO is not a one man thing. Have to make sure everybody understands and have the right mindset."

\section{Conclusion}

After analyzing the survey questionnaires and interviews, it seems that most of the construction firms in Singapore are ready to transit to ISO 9001:2008. The process of converting appears to be fairly easy to bring about better clarification for the organization. However, at the time of the study, it was not the top priority for some of the construction firms.

Organizational behavior does not seem to play an important impact on the process of transiting to the ISO 9001:2008 certification. Firstly, the system for quality management and organizational environment is already in place. No drastic measures or changes need to be implemented for the organization to adopt the new ISO standards. Secondly, there appears to be no need to utilize large amount of resources such as manpower and money to transit to ISO 9001:2008. 
The fieldwork highlighted the following important points:

1. Construction companies in Singapore appear to be aware of the ISO 9001:2008 standards and they know that the transition does not include major changes to the existing requirements. Most of the companies are planning for certification while a minority of them appears to be taking their time.

2. Organizational behavior may appear to play an important role when transiting from ISO 9000:1994 to ISO 9001:2000. However, this does not seem to be the case for the transition from ISO 9001:2000 to ISO 9001:2008. The reason appears to be due to the lack of an emphasis on ISO 9001:2008 from the government and the organization. The process of transiting to ISO 9001:2008 appears simple and flexible such that it does not affect the organization's daily functions, resources or environment.

3. To accomplish successful implementation of a good quality management system, top management and the employees must play their part. ISO certification is not only about documenting manuals but it is also about putting the standards into daily practice within the organization.

The study recommends that construction firms in Singapore should treat ISO certification seriously. There is no doubt that the documentation and manuals have to be properly managed and maintained. It will also be best to implement good quality practices in the daily routine of the organization.

Construction firms should be more active in adopting the latest ISO certification to improve on their quality management systems. In addition, the organization should ensure that all employees have a part to play in managing and supporting quality management.

\section{References}

Hackman J. R., Lawler E. and Porter L. (1983) Perspectives on behavior in organizations, McGraw-hill Professional, US.

Hersey P., Blanchard K. H. and Johnson D. E. (2000) Management of organizational behavior: leading human resources, Prentice Hall, UK.

Hoyle D. (2009) ISO 9000 Quality Systems Handbook. Using the standards as a framework for business improvement, Elsevier Ltd., UK.

Miner J. B. (2007) Organizational behavior: From theory to practice, M. E. Sharpe, US.

Scott W. R. (2001) Institutions and Organizations, Second Edition, Sage, Thousand Oaks, CA. 
Scott W. R. (2004) Institutional theory, in Ritzer G (ed.) Encyclopedia of Social Theory, Sage, Thousand Oaks, CA, pages 408-414.

Sims R.R. (2002) Managing Organizational Behavior, Greenwood Press, UK.

Stapp E. H. (2001) ISO 9001:2000: an essential guide to the new standard, QA Publishing LLC, Australia.

Thompson L. (2007) Organizational Behavior Today, Pearson Education, UK.

Tricker R. (2006) ISO 9001:2000: The Quality Management Process, Van Haren Publishing, UK.

Weallans D. (2000) The Quality Audit for ISO 9001:2000, Gower Publishing Company, UK.

Table 1 The three pillar framework

\begin{tabular}{|l|l|l|l|}
\hline & \multicolumn{3}{|c|}{ Structure and activities } \\
\hline Characteristics & Cognitive & Normative & Regulative \\
\hline Basis of compliance & Taken for granted & Social Obligation & Expedience \\
\hline Mechanisms & Imitation & Normative & Coercive \\
\hline Logic & Orthodoxy & Appropriateness & Instrumentality \\
\hline Indicators & Prevalence & Accreditation & Rules \\
\hline & Isomorphism & & Laws \\
\hline & & & Sanctions \\
\hline Basis of legitimacy & Culturally supported & Morally governed & Legally sanctioned \\
\hline & Conceptually correct & & \\
\hline Carriers & & & Rules \\
\hline Cultures & Categories & Values & Laws \\
\hline & Typifications & Expectations & Government systems \\
\hline Social Structures & Isomorphism & Regimes & Power systems \\
\hline & Identities & Authority systems & Protocols \\
\hline Routines & Performance programs & Conformity & Standard procedures \\
\hline & Scripts & Performance of duty & \\
\hline & & & \\
\hline
\end{tabular}

(Source: adapted from Scott, 2001, 2004) 